\title{
Effects of the Photoperiod on the Growth of Rhizome in Polygonum conspicuum
}

\author{
by Yasumasa SAWAMURA*
}

Received May 7, 1970

\begin{abstract}
Polygonum conspicuum, a perennial knotweed, is a sensitive short-day plant. It develops several long, branched rhizomes in a year. Effects of the photoperiod on the growth of rhizomes were investigated with this plant. Young plants grown from the cuttings were placed under $12 \frac{1}{2}-, 13 \frac{1}{2}-, 14 \frac{1}{2}$, and 24-hour photoperiods and under the natural conditions from May to October, 1.968. Observations made at intervals of a month showed that the total length and the branching of rhizomes were much increased under $12 \frac{1}{2}$-hour photoperiods as compared with those under other longer photoperiods. Seven cycles of 8-hour photoperiods given in June or July also caused the promoted branching of rhizomes.

Under natural conditions, the branching of rhizomes was much promoted from September to October. This may be due to the shorter daylength during these

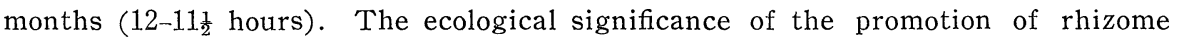
branching by short days is discussed.
\end{abstract}

The effects of photoperiod on the formation of underground storage organs such as bulbs and tubers have been studied by many authors with the onion ${ }^{1,2,3)}$, the potato ${ }^{4,5,6)}$ and the archchoke ${ }^{7}$. The short photoperiods are effective in some plants and in other plants the long photoperiods. It has been known in some plants that the formation of stolons or runners is influenced by photoperiod. In a variety of the strawberry ${ }^{8}$, the 14 -hour photoperiods were neccessary for runner formation. In a mountain form of Polygonum thunbergi $i i^{9)}$, the short photoperiods promoted the stolon formation. However, the effects of photoperiod on the growth of rhizomes have been little studied. In Polypara cordata ${ }^{10)}$, 15-, 12-hour photoperiods exerted a more marked effect on the growth in length and in fresh weight of the rhizome than those of longer or shorter duration did.

Polygonum conspicuum, a perennial knotweed, is a sensitive shart-day plant ${ }^{11)}$. It develops several long, branched rhizomes in a year even when grown from the cutting (Fig. 4, A, B), and is a very suitable plant for studying the effect of photoperiod on the rhizome development. In this paper the photoperiodic response of the rhizome of Polygonum conspicuum will be reported with a brief consideration of its ecological significance.

\section{Material and Methods}

In April, 1968, newly sprouted shoots of Polygonum conspicuum were collected from the field and grown from the cuttings. Early in May, the rooted cuttings were selected for uniformity and planted in 18-cm clay pots. They showed good growth.

* Department of Biology, Faculty of Education, Mie University, Tsu, Japan. 
To investigate the photoperiodic response of the rhizome, two kinds of experiments were conducted. In the first or the constant photoperiod experiment, lots of 50 plants each were subjected to $12 \frac{1}{2}-, 13 \frac{1}{2}-, 14 \frac{1}{2}$ and 24 -hour photoperiods, respectively, throughout the experimental period (in abbreviation $12 \frac{1}{2} \mathrm{~L}, 13 \frac{1}{2} \mathrm{~L}, 14 \frac{1}{2} \mathrm{~L}$ and $24 \mathrm{~L}$ ). The experiment was begun on May 22 and closed on October 22, 1968. In the second experiment, 30 plants were subjected to 7 cycles of 8 -hour photoperiods in June or July, 1968 (in abbr. 8L-VI and 8L-VII) and kept under the continuous illumination before and after the treatment.

The method for photoperiodic treatments was the same as that used previously in the case of Polygonum thunbergii ${ }^{12}$. In $24 \mathrm{~L}$ and for the continuous illumination, the plants were illuminated all night by two 200 -watt incandescent lamps equipped 2 meters above the plants.

To examine the response of the rhizome to the treatments in the first experiment, 10 plants were picked out randomly from each lot at intervals of about a month. They were observed for the total fresh weight, the total length and the branching of the rhizomes. In the second experiment, the same observations were made a month after the flowering induced by the treatment.

For comparison, 50 plants were kept under the natural conditions and examined in the same manner.

\section{Results}

A. The constant photoperiod experiment.

1. The total length of rhizomes.

The plant of $P$. conspicuum developed several branched rhizomes.

The lengths of the main rhizomes and their branches of each plant were measured and summed up. The average of these values in each lot will be referred to as the total length of rhizomes. As seen in Fig. 1, the effect of the photoperiod on the growth of rhizomes appeared as early as 2 months after the start of the experiment. Under $12 \frac{1}{2} \mathrm{~L}$ the total length of rhizomes exceeded those under other photoperiods throughout the experimental period. On October 22, the

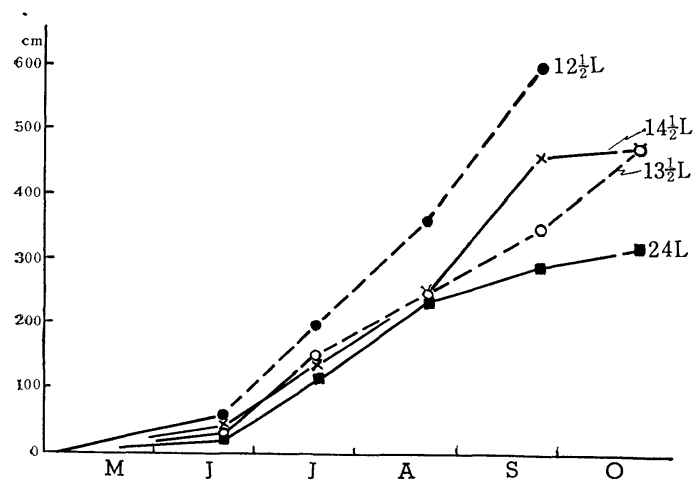

Fig. 1. Effects of photoperiods on the total length of rhizomes of $P$. conspicuum. The broken line of the curve indicates that the plants came into flower. total lengths under $13 \frac{1}{2} \mathrm{~L}$ and $14 \frac{1}{2} \mathrm{~L}$ were longer than that under $24 \mathrm{~L}$.

In this short-day plant, flower initiation occurred under $12 \frac{1}{2} \mathrm{~L}$ and $13 \frac{1}{2} \mathrm{~L}$, and the flowering brought about the senescence of the leaves gradually. This may be at least one of the factors responsible for the promoted growth of rhizomes under these photoperiods. It is known in potato that the senescence of the aboveground part is associated with the swelling of tubers ${ }^{13}$.

2. The branching of rhizomes.

The branching of rhizomes was 
expressed by the number of main rhizomes plus the number of primary and secondary branches. The branch shorter than $2 \mathrm{~cm}$ was neglected. As seen in Fig. 2, the branching increased with decreasing length of photoperiods. The branching is generally reflected in the total length of rhizomes.

\section{The total fresh weight of rhizomes.}

As shown in Fig. 3, the rhizome weight measured on July 18 decreased with the increase in length of photoperiods, the value for $12 \frac{1}{2} \mathrm{~L}$ being especially high. But in the later season the rhizome weight had no correlation with photoperiods.

The formation of the starch grains within the rhizome began from the outset of its growth and continued to autumn, resulting in their accumulation over the whole length (Fig. 4, H, I). The fresh weight of the rhizomes may be influenced by such starch accumulation. Microscopic observations, however, failed to detect any effect of photoperiods on the starch accumulation.

B. The effects of 7 cycles of 8 -hour photoperiods.

The 8-hour photoperiod treatment given for 7 consecutive days induced all the plants to flower. They formed visible inflorescences about 3 weeks after the start of treatment. As stated above, the effects of the treatments were examined just a month after the inflorescence formation. As these plants were kept under the continuous illumination before and after the treatment, the results obtained in $24 \mathrm{~L}$ were utilized as the control. Fig. 5 shows that the treatment brought about a slight suppression in the total length and in the total fresh weight of rhizomes. However, the treatment resulted in the increased branching of rhizomes.

C. The rhizome development under natural conditions.

As Fig. 6 shows, the growth in length of the rhizome was vigorous in July and August, when long photoperiods and high temperature governed the natural conditions. The total fresh weight increased gradually, forming a typical growth curve. In contrast, the curve of the branching rose upward from near the end of September to October, when the natural daylength was from 12 to $11 \frac{1}{2}$ hours at Tsu $\left(34_{3}^{2}{ }^{\circ} \mathrm{N}\right)$ where the experiments were carried out. The increase in branching may have been induced by these shorter photoperiods.

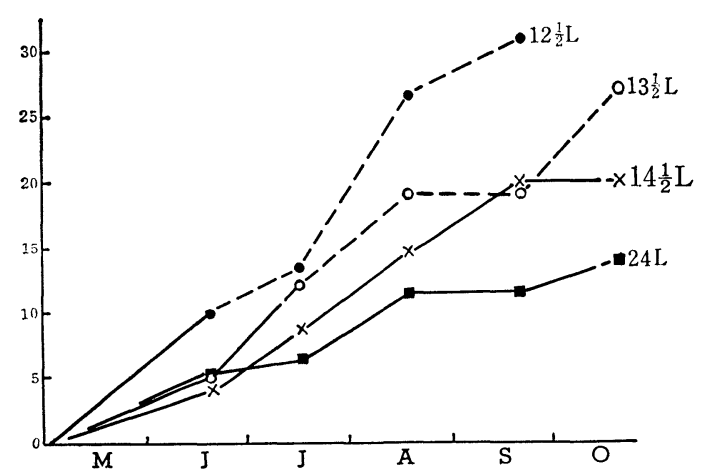

Fig. 2. Effects of photoper ods on the branching of rhizomes of $P$. conspicuum.

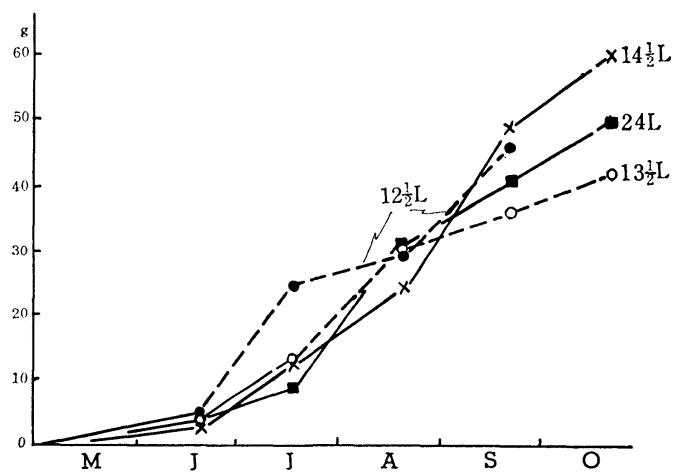

Fig. 3. Effects of photoperiods on the fresh weight of rhizomes of $P$. conspicuum. 

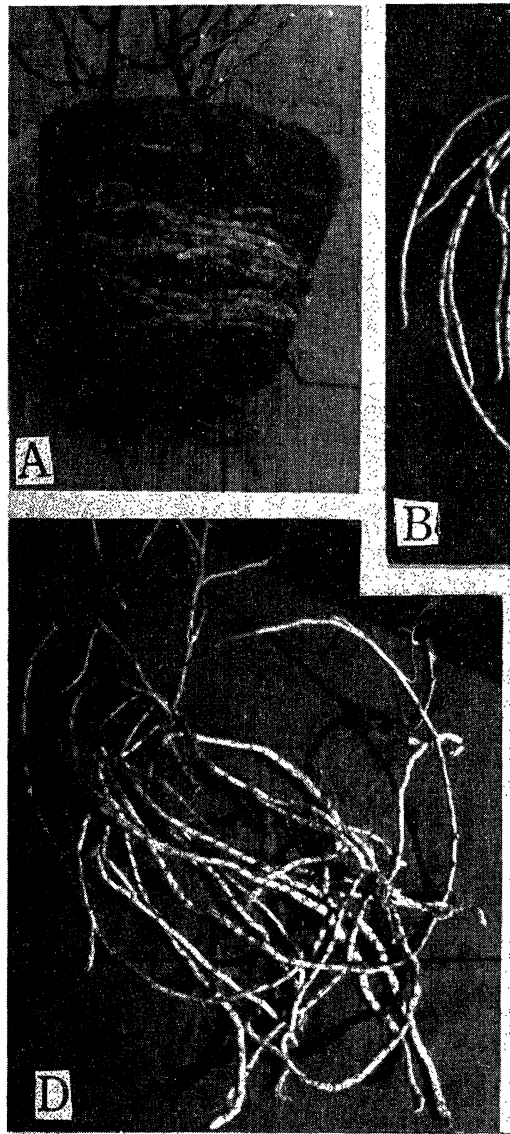
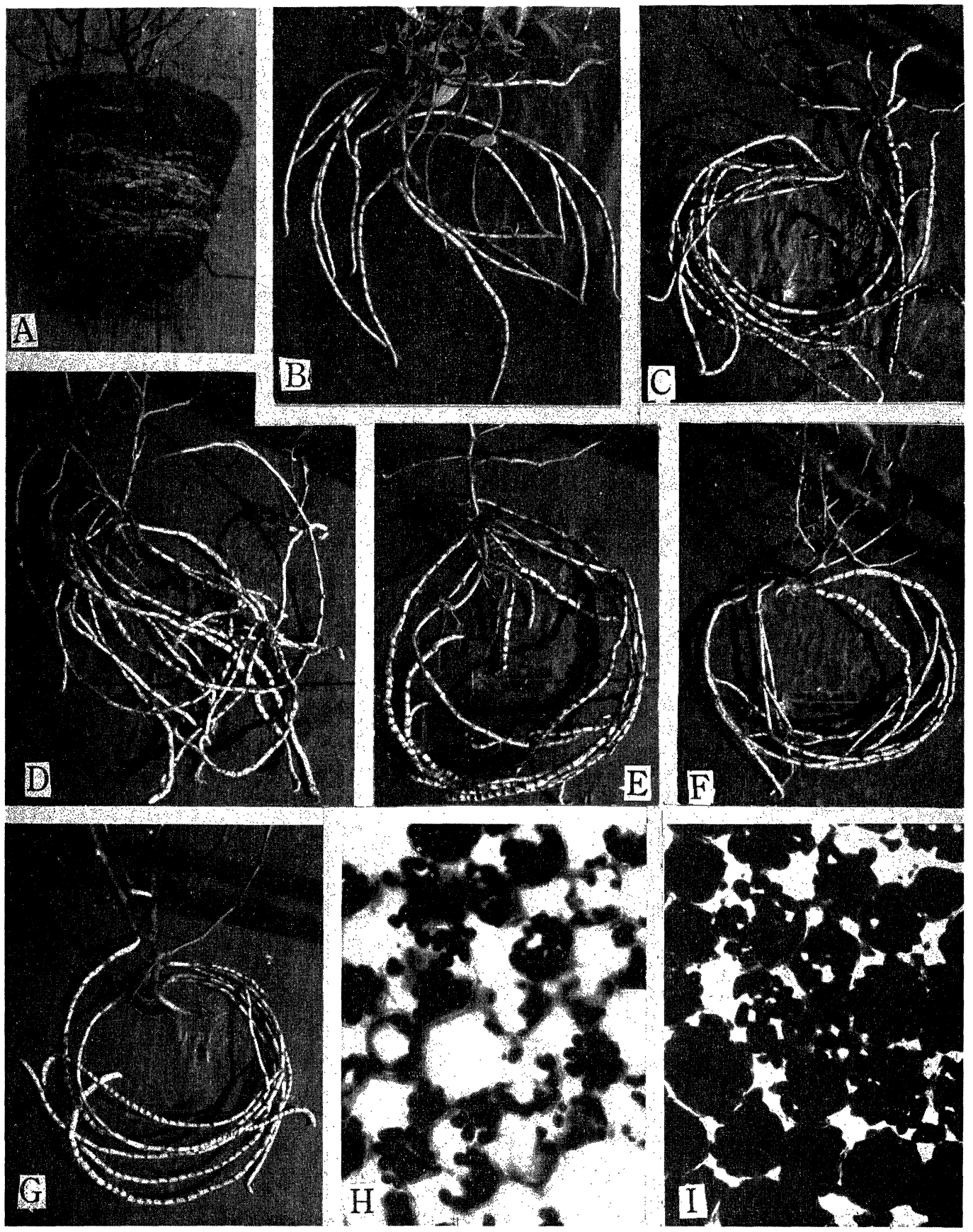

Fig. 4. The growth of rhizome of $P$. conspicuum under various photoperiods.

A : Rhizomes developed inside the pot under 24L (Sept. 22).

B : Rhizomes of a plant kept under $12 \frac{1}{2} \mathrm{~L}$ (July 18).

C, D, E, F, G: Rhizomes of the plants kept under the natural conditions, $12 \frac{1}{2} \mathrm{~L}, 13 \frac{1}{2} \mathrm{~L}, 14 \frac{1}{2} \mathrm{~L}$ and $24 \mathrm{~L}$ respectively (Sept. 22).

H, I: Starch grains within the rhizomes of the plants kept under $13 \frac{1}{2} \mathrm{~L}$ (June 20) and under the natural condition (Sept. 22) respectively. 


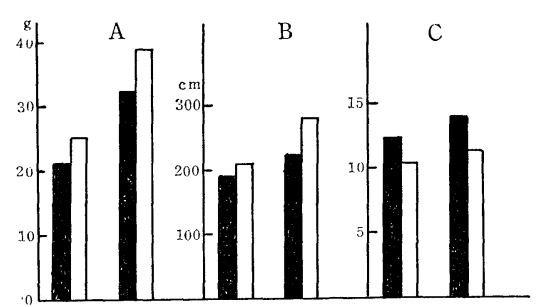

Fig. 5. Effects of 7 cycles of 8-hour photoperiods on the growth of rhizomes of $P$. conspicuum.

$A$, total length; $B$, fresh weight; $C$, number of branching.

Solid bars, treated; open bars, controls. Left pairs, 8L-VI (examined on Aug. 12) ; right pairs, 8L-VII (examined on Sept. 16).

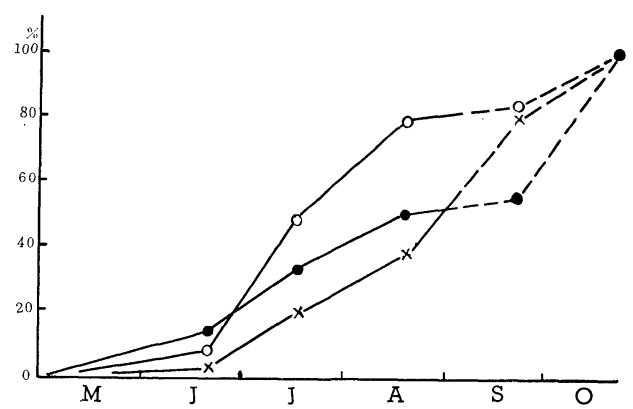

Fig. 6. The growth of rhizomes of $P$. conspicuum under the natural conditions at Tsu.

All the values are represented as the percentages of those obtained on Oct. 22.

\section{Conclusion}

From the results describd above, it was revealed that of the examined effects of photoperiod on the growth of rhizomes in $P$. conspicuum, the effect on the branching was the most consistent. It may be concluded that the branching of rhizomes in this species is promoted under short-day conditions. The apex of rhizome grows up into a hibernation bud, which will sprout up into a new shoot next spring, resulting in the vegetative propagation. Thus, the promotion of rhizome branching by the shorter photoperiod in autumn may be favorable for the plant to propagate. Bulbs, tubers, stolons and rhizomes are the organs of vegetative propagation. As mentioned above, in some plants their formation and swelling are promoted by the photoperiods in the season of formation or swelling. The branching of the rhizome in $P$. conspicuum may be one of these photoperiodic adaptations.

It is a pleasure of the writer to acknowledge here the cooperation of Miss Kaneko Kawai and Miss Masako Asai in the whole course of this study.

\section{References}

1) Magruder, R. and Allard, H. A., J. Agr. Res. $54: 715$ (1937).

2) Thompson, H.C. and Smith, O., Cornell Univ. Expt. Sta. Bul. 708 (1934).

3) Allard, H.A. and Garner, W.W., U.S. Dept. Agr. Tech. Bul. 727 (1940).

4) Miller, J.C. and McGoldrick, F., Am. Potato Jour. 18 : 261 (1941).

5) Werner, H. O., Am. Potato Jour. 12: 274 (1935).

6) Madec, P. and Perennec, P., Ann. Physiol. Vegetale 4: 5 (1962).

7) Zimmerman, P.W. and Hitchcock, A.E., Contrib. Boyce Thompson Inst. 8: 311
(1936).

8) Hartmann, H. T., Plant Physiol. 22: 407 (1947).

9) Sawamura, Y., Bot. Mag. Tokyo 82: 183 (1969).

10) Iizumi, S., Sci. Rep. Tohoku Univ., 4th Ser. 19 : 40 (1951).

11) Sawamura, Y., Bul. Lib. Arts Dept. Mie Univ. 10: 33 (1953).

12) —, Jap. Jour. Bot. 19:353 (1967).

13) Wassink, E.C. and Stolwijk, J.A. J., Mededel. Landbouwhogeschool Wageningen 53 : 99 (1953). 